\title{
Reactive Oxygen Species Mediate p53 Activation and Apoptosis Induced by Sodium Nitroprusside in SH-SY5Y Cells ${ }^{[}$
}

\author{
Simone Cardaci, Giuseppe Filomeni, Giuseppe Rotilio, and Maria R. Ciriolo \\ Department of Biology, University of Rome "Tor Vergata," Rome, Italy (S.C., G.F., G.R., M.R.C.); \\ and Research Centre Istituto di Ricovero e Cura a Carattere Scientifico San Raffaele "La Pisana," Rome, Italy \\ (G.F., G.R., M.R.C.)
}

Received May 19, 2008; accepted August 1, 2008

\begin{abstract}
Sodium nitroprusside (SNP) is a water-soluble iron nitrosyl complex clinically used as a powerful vasodilator for treatment of hypertension; and, in basic research, it has been used to mainly investigate the cytotoxic effects of nitrosative stress. Although NO is considered a pharmacologically active molecule, not all of the biological effects of SNP are dependent on its NO moiety. To elucidate the molecular executioner(s) responsible for SNP cytotoxicity, this study determines the involvement of oxidative stress in p53 activation and apoptotic induction elicited by SNP in SH-SY5Y neuroblastoma cells. We demonstrate that proapoptotic activity of SNP is independent of NO production, because SNP and its 2-day light-exhausted compound $\mathrm{SNP}_{\text {ex }}$ trigger apoptosis to the same extent. We provide evidence for the occurrence of oxidative stress and oxidative damage during both SNP and $\mathrm{SNP}_{\mathrm{ex}}$ exposure and
\end{abstract}

demonstrate that iron-derived reactive oxygen species (ROS) are the genuine mediators of their cytotoxicity. We show that p53 is equally activated upon both SNP and SNP ex treatments. Moreover, as demonstrated by small interfering RNA experiments, we indicate its primary role in the induction of apoptosis, suggesting the ineffectiveness of NO in its engagement. The attenuation of p53 levels, obtained by oxy-radical scavengers, is consistent with the recovery of cell viability and ROS decrease, demonstrate that SNP-mediated p53 activation is an event triggered by ROS and/or ROS-mediated damages. Together, our results suggest that investigations of the physiopathological effects of SNP should consider the role of ROS, other than NO, particularly in some conditions such as apoptotic induction and p53 activation.
NO is a diffusible and reactive free radical involved in a wide range of physiological functions, including the control of vascular tone, platelet aggregation, and the immune response (Moncada et al., 1991; Mannick, 2006). In the central nervous system, NO plays a pivotal role as neurotransmitter, neuromodulator, and neuroprotector, even if alteration in its synthesis is detrimental for neuronal cell viability. In fact,

The work was partially supported by grants from Ministero della Salute (to M.R.C.)

S.C. and G.F. contributed equally to this work.

Article, publication date, and citation information can be found at http://molpharm.aspetjournals.org.

doi:10.1124/mol.108.048975.

$\mathrm{S}$ The online version of this article (available at http://molpharm. aspetjournals.org) contains supplemental material. during its overproduction, $\mathrm{NO}$ acts as a proapoptotic molecule, activating mainly the mitochondrial apoptotic pathway by modulating the expression of apoptosis-associated proteins such as Bax and Bcl-2 (Brüne, 2005; Pacher et al., 2007). Moreover, sustained production of NO and its reactive nitrogen species (RNS) leads to DNA damage, promoting the activation of the tumor suppressor p53 protein, which in turn can activate transcription of regulatory genes, allowing DNA repair, or programmed cell death (Brüne and Schneiderhan, 2003; Vousden and Lane, 2007).

In general, pathophysiological processes controlled by NO and RNS are investigated by using NO donors with different half-lives, chemical properties, and kinetics of release. One of the most known NO-releasing drugs is the nitroferricyanide

ABBREVIATIONS: RNS, reactive nitrogen species; SNP, sodium nitroprusside; ROS, reactive oxygen species; AMS, ammonium sulfamate; DMSO, dimethyl sulfoxide; DMTU, dimethyl thiourea; DEF; deferoxamine mesylate; TEMPOL, 4-hydroxy-2,2,6,6-tetramethylpiperidine- $N$-oxyl; DMEM, Dulbecco's modified Eagle's medium; $\mathrm{SNP}_{\text {ex }}$, photoexhausted sodium nitroprusside; PBS, phosphate-buffered saline; siScr, scramble small interfering RNA duplex; $\mathrm{NO}_{x}$, nitrites and nitrates; PAGE, polyacrylamide gel electrophoresis; Hsp, heat shock protein; PARP, poly(ADPribose) polymerase; GSH, reduced glutathione; GSSG, glutathione disulfide; DCFH-DA, 2',7'-dichlorodihydrofluorescein diacetate; DNP, 2,4dinitrophenylhydrazine; siRNA, small interfering RNA; zVAD-fmk, benzyloxycarbonyl-Val-Ala-Asp-fluoromethyl ketone; P-H2A.X, phosphoactive histone H2A.X. 
or disodium nitroprusside ( $\mathrm{SNP}) \mathrm{Na}_{2}\left[\mathrm{NO}-\mathrm{Fe}(\mathrm{CN})_{5}\right]$, a watersoluble iron nitrosyl complex consisting of a ferrous ion surrounded by five cyanide moieties and a nitrosyl group. On the basis of its very short half-life, as well as of the immediate and rapid dissipation of its bioactivity, SNP has been clinically used as a powerful vasodilator for treatment of cardiac failures and all forms of hypertensive emergencies; and, in basic research, it has been used to mainly investigate the apoptotic mechanisms triggered under conditions of nitrosative stress (Chen et al., 1991; Friederich and Butterworth, 1995; Li et al., 2004).

It is well documented that NO is the molecule responsible for many pharmacological and toxicological effects elicited by SNP. Nevertheless, several in vitro studies revealed that many other biological properties of SNP are independent of the NO moiety because of the huge number of by-products released during its decomposition, such as cyanide, iron, and reactive oxygen species (ROS), which could account predominantly for SNP bioactivity. For example, it has been recently demonstrated that the ability of SNP to induce heme oxygenase-1 expression (Kim et al., 2006) and iron regulatory protein 2 degradation (Wang et al., 2006) is not tightly dependent on NO release but rather is mediated by the release of its iron moiety. Moreover, it has been demonstrated that hydrogen peroxide production is implicated in SNP-induced cardiomyocyte death (Rabkin and Kong, 2000), and a synergism between NO and the FeCN portion of SNP has been hypothesized to be functional for SNP-induced oligodendrocyte apoptosis (Boullerne et al., 1999).

In the attempt to elucidate the molecular mechanisms underlying SNP cytotoxicity, the current study investigates in detail the role played by oxidative stress in p53 activation and commitment of SH-SY5Y neuroblastoma cells to cell death.

\section{Materials and Methods}

Materials. SNP was from Alexis Corporation (Lausen, Switzerland). Ammonium sulfamate (AMS), dimethyl sulfoxide (DMSO), dimethylthiourea (DMTU), EDTA, EGTA, paraformaldehyde, propidium iodide, deferoxamine mesylate (DEF), TEMPOL, and Triton X-100 were from Sigma-Aldrich (St. Louis, MO). Goat anti-mouse and anti-rabbit IgG $(\mathrm{H}+\mathrm{L})$-horseradish peroxidase conjugate was from Bio-Rad (Hercules, CA). All other chemicals were obtained from Merck (Darmstadt, Germany).

Cell Culture. Rat phaeochromocytoma PC12 cells were grown in DMEM containing $15 \%$ horse serum, $2.5 \%$ fetal bovine serum, and $1 \%$ penicillin/streptomycin. Human neuroblastoma SH-SY5Y and gastric adenocarcinoma AGS cell line were purchased from the European Collection of Cell Culture (Salisbury, Wiltshire, UK) and grown in Dulbecco's minimal essential medium/F-12 and in F-12 medium, respectively. Murine motor neuron $\times$ neuroblastoma hybrids NSC34 were kindly provided by Dr. Neil R. Cashman (University of Toronto, Toronto, ON, Canada) and grown in DMEM. Except for PC12, all other cell media were all supplemented with $10 \%$ fetal calf serum, $1 \%$ penicillin/streptomycin, and $1 \%$ glutamine. The cells were maintained at $37^{\circ} \mathrm{C}$ in a $5 \% \mathrm{CO}_{2}$ atmosphere in air and routinely trypsinized, plated at $4 \times 10^{4}$ cells $/ \mathrm{cm}^{2}$ in a flask. Cell viability was assessed by trypan blue exclusion.

Treatments. A $0.5 \mathrm{M}$ solution of SNP or ferricyanide $\left[\mathrm{Fe}(\mathrm{CN})_{6}\right]$ (Merck) was prepared just before the experiments by dissolving the powders in water. Treatments were performed at final concentrations ranging from 0.5 to $2 \mathrm{mM}$, in medium supplemented with serum. As control, equal volumes of water were added to untreated cells. Exhausted SNP $\left(\mathrm{SNP}_{\mathrm{ex}}\right)$ was obtained by leaving the solution of
SNP under light exposure for 2 days at room temperature as reported previously (Wang et al., 2006). Then, $2 \mathrm{mM} \mathrm{SNP}$ or $\mathrm{SNP}_{\mathrm{ex}}$ was selected for all the experiments because it allowed for evaluation of a reliable degree of apoptosis in a time window of $24 \mathrm{~h}$, and because $2 \mathrm{mM}$ is the concentration close to the $\mathrm{EC}_{50}$ of the SNP in SH-SY5Y cells. AMS was used at a final concentration of $10 \mathrm{mM}$, added with SNP, and maintained throughout the experiment. The pan-caspase inhibitor zVAD-fmk (Alexis Corporation) was used at a final concentration of $20 \mu \mathrm{M}$, preincubated for $1 \mathrm{~h}$ before the addition of SNP or $\mathrm{SNP}_{\mathrm{ex}}$, and maintained throughout the experimental time. The cellpermeable hydroxyl radical scavengers (DMTU, DMSO, and TEMPOL) were used at final concentrations of $20 \mathrm{mM}, 3 \mu \mathrm{M}$, and $1.5 \mu \mathrm{M}$, respectively, added with SNP, and maintained throughout the experiment. Likewise, the iron chelator DEF was used to reach the final concentrations of $100 \mu \mathrm{M}$. Then, $2 \mathrm{mM}$ thiosulfate, a rhodanese substrate, or $1 \mu \mathrm{M}$ purified antioxidant enzymes catalase or superoxide dismutase was added $1 \mathrm{~h}$ before SNP addition and maintained in the medium throughout the experimental time.

Analysis of Cell Viability and Apoptosis. Adherent (after trypsinization) and detached cells were combined, washed with PBS, and stained with $50 \mu \mathrm{g} / \mathrm{ml}$ propidium iodide before analysis by a flow cytometer (FACSCalibur; BD Biosciences, San Jose, CA). The percentages of apoptotic cells were evaluated according to Nicoletti et al. (1991) by calculating peak area of hypodiploid nuclei (sub- $\mathrm{G}_{1}$ ).

Measurement of Nitrite and Nitrate Concentration. NO released from SNP was indirectly quantified by measuring the oxidation by-products nitrites and nitrates $\left(\mathrm{NO}_{\mathrm{x}}\right)$. Analyses of $\mathrm{NO}_{\mathrm{x}}$ concentration were done either in water or cell media by the reaction with the Griess reagent according to Kotsonis et al. (1999). Total $\mathrm{NO}_{\mathrm{x}}$ were measured upon nitrate reductase-mediated reduction of nitrates. The concentration of $\mathrm{NO}_{\mathrm{x}}$ was determined by a standard curve obtained with known amount of sodium nitrite and expressed as micromolar concentration.

Western Blot Analyses. Total protein extracts were obtained by rupturing cells with 30 min of incubation on ice in lysis buffer (50 mM Tris-HCl, pH 7.4, 1 mM EDTA, 1 mM EGTA, 1\% Triton X-100, $10 \mathrm{mM} \mathrm{NaF}$, and $1 \mathrm{mM}$ sodium orthovanadate) and protease inhibitor cocktail (Roche Applied Science, Monza, Italy) followed by centrifugation at $22,300 \mathrm{~g}$ for $20 \mathrm{~min}$ at $4^{\circ} \mathrm{C}$. Protein extracts were then separated by SDS-PAGE and blotted onto nitrocellulose membrane (Bio-Rad). Monoclonal anti-p53 (clone BP5312), anti-actin (SigmaAldrich), anti-procaspase-3 (clone3G2; Cell Signaling Technology Inc., Danvers, MA), anti-poly(ADP-ribose) polymerase (PARP) (Santa Cruz Biotechnology, Inc., Santa Cruz, CA), and anti-Hsp90 (BD Biosciences, Franklin Lakes, NJ) and polyclonal anti-p21, antiBax (Santa Cruz Biotechnology, Inc.), and anti-procaspase-9 (Cell Signaling Technology Inc.) were used as primary antibodies. The specific protein complex, formed upon specific secondary antibody treatment, was identified using a FluorChem Imaging system (Alpha Innotech, Analitica De Mori, Milano, Italy) after incubation with ChemiGlow chemiluminescence substrate (Alpha Innotech).

Measurement of Glutathione, ROS Levels, and Carbonylated Proteins. Intracellular reduced (GSH) and oxidized (GSSG) forms of the tripeptide glutathione were assayed upon formation of $S$-carboxymethyl derivatives of free thiols with iodoacetic acid, followed by the conversion of free amino groups to 2,4-dinitrophenyl derivatives by the reaction with 1-fluoro-2,4-dinitrobenzene as described previously (Filomeni et al., 2003b). Detection of intracellular ROS by 2',7'-dichlorodihydrofluorescein diacetate (DCFH-DA; Invitrogen, Carlsbad, CA), was performed as described previously (Filomeni et al., 2003a). Carbonylated proteins were detected using the Oxyblot kit (Serologicals Corp., Norcross, GA) after reaction with 2,4-dinitrophenylhydrazine (DNP) for $15 \mathrm{~min}$ at $25^{\circ} \mathrm{C}$. Samples were then resolved by $10 \%$ SDS-PAGE, and DNP-derivatized proteins were identified by immunoblot using an anti-DNP antibody (Filomeni et al., 2007).

Fluorescence Microscopy Analyses. Cells were plated on chamber slides at $6 \times 10^{4} / \mathrm{cm}^{2}$, fixed with $4 \%$ paraformaldehyde, and 
permeabilized. Afterward, they were washed exhaustively with PBS; blocked with PBS containing $10 \%$ fetal calf serum; incubated with a monoclonal anti-Ser-139-phosphorylated histone H2A.X antibody (clone JBW301; Millipore, Billerica, MA), in combination with a polyclonal anti-p53 antibody (Sigma-Aldrich); and further probed with Alexa Fluor-488 and Alexa Fluor-568-conjugated secondary antibodies (Invitrogen), respectively. To visualize nuclei, cells were also incubated with the cell-permeable DNA dye Hoechst 33342 (Calbiochem-Novabiochem, San Diego, CA), washed with PBS, and analyzed by fluorescence microscopy.

To evaluate mitochondrial integrity, cells were stained with $50 \mathrm{nM}$ MitoTracker Red (Invitrogen), a mitochondrial transmembrane potential-sensitive probe; washed; and analyzed cytofluorometrically. Alternatively, they were fixed with $4 \%$ paraformaldehyde and analyzed by fluorescence microscopy.

Images of cells were digitized with a CoolSnap video camera connected to Nikon Eclipse TE200 fluorescence microscopy (Nikon, Tokyo, Japan). All images were captured under constant exposure time, gain, and offset.

Iron Determination. Cell pellets were diluted 1:2 with $65 \% \mathrm{HNO}_{3}$. After 1 week at room temperature, iron concentration was measured by atomic absorption spectrometry using an AAnalyst 300 spectrometer (PerkinElmer Life and Analytical Sciences, Waltham, MA), equipped with a graphite furnace with platform HGA-800 and an AS-72 auto sampler.

siRNA Transfections. Twenty-four hours after plating, 50\% confluent SH-SY5Y cells were transfected with a 21-nucleotide siRNA duplex directed against the p53 mRNA target sequence 5'-GACUCCAGUGGUAAUCUACTT-3' (sip53) (MWG Biotech, Ebersberg, Germany). Control cells were transfected with a scramble siRNA duplex, which does not present homology with any other human mRNAs (siScr). Cells were transfected by electroporation using a Gene Pulser Xcell system (Bio-Rad) according to the manufacturer's instructions and immediately seeded into fresh medium. Transfection efficiency of siRNA into SH-SY5Y cells was estimated by cotransfecting p53 siRNA with nonspecific rhodamine-conjugated oligonucleotides and found to be $>80 \%$.

Protein Determination. Proteins were determined by the method of Lowry et al. (1951).

Data Presentation. All experiments were done at least three different times unless otherwise indicated. Data are expressed as means \pm S.D., and significance was assessed by Student's $t$ test corrected by Bonferroni's method. Differences with $p$ values $<0.05$ were considered significant.

\section{Results}

SNP Induces Caspase-Dependent Apoptosis in SHSY5Y Cells. Although NO is considered the active component of SNP, an increasing number of reports indicate that several SNP-elicited cellular effects are NO-independent (Kim et al., 2006; Wang et al., 2006). To investigate the genuine mediators of neurotoxic effects triggered by SNP exposure, we treated SH-SY5Y cells, which have been demonstrated previously to be sensitive to NO-induced programmed cell death (Ciriolo et al., 2000), with different concentrations of SNP, ranging from 0.5 to $2 \mathrm{mM}$. Figure $1 \mathrm{~A}$ shows cytofluorometric analyses of SH-SY5Y cells treated with SNP for $24 \mathrm{~h}$ : plots displayed a dose-dependent increase in the percentage of apoptotic and $\mathrm{G}_{2} / \mathrm{M}$ phase-blocked cells. These data are in agreement with results obtained previously on SH-SY5Y treated with the same concentrations of SNP (Ghatan et al., 2000; Feng et al., 2002; Li et al., 2004). We then evaluated whether SNP treatment triggered a caspasedependent apoptotic process by means of the activation of the mitochondrial pathway. Figure $1 \mathrm{~B}$ shows that 12 -h treat- ment with SNP induced a significant decrease of procaspase- 9 and procaspase- 3 immunoreactive bands. This event was associated with the proteolysis of PARP. To confirm the occurrence of a caspase-mediated apoptotic response upon SNP treatment, we incubated the cells for $1 \mathrm{~h}$ with the pan-caspase inhibitor zVAD-fmk before the addition of SNP, and we measured cytofluorometrically the apoptotic extent after $24 \mathrm{~h}$ of treatment. Figure 1C shows that cell viability was recovered by inhibiting caspase activation, confirming that caspase-mediated apoptosis was the principal mechanism of cell death induction in our experimental conditions.

Thus, to evaluate a correlation between apoptosis commitment and NO release, we analyzed the concentration of $\mathrm{NO}_{\mathrm{x}}$ produced in cell medium up to $24 \mathrm{~h}$ of SNP treatment. Figure $1 \mathrm{D}$ shows that addition of SNP to culture media induced a time- and dose-dependent increase in the $\mathrm{NO}_{\mathrm{x}}$ levels, suggesting that SNP toxicity could be related to NO production.

Apoptotic Induction Is Not Related to NO and Cyanide Moieties of SNP. To verify a direct causative role of NO moiety in the apoptotic process, we incubated SH-SY5Y cells with the 2-day photodegraded $\mathrm{SNP}\left(\mathrm{SNP}_{\mathrm{ex}}\right)$, which corresponds to its derived NO-exhausted compound (Wang et al., 2006). The histograms in Fig. 2A show that, surprisingly, $\mathrm{SNP}_{\mathrm{ex}}$ still induced apoptosis with the same trend of the freshly prepared SNP, demonstrating that NO is not the exclusive molecule involved in the induction of apoptosis in SH-SY5Y cells.

To assess whether incomplete photodegradation of SNP could account for the similar effects of SNP and $\mathrm{SNP}_{\mathrm{ex}}$ on cell viability, we verified the effective $\mathrm{NO}$ exhaustion by analyzing the kinetic of $\mathrm{NO}_{\mathrm{x}}$ production. Figure $2 \mathrm{~B}$ shows that the content of $\mathrm{NO}_{\mathrm{x}}$, obtained after dissolving $2 \mathrm{mM}$ SNP in water or cell medium under conditions of light exposure increased up to 2 days, after which a plateau was reached that remained almost unchanged during the subsequent 7 days.

Results showed that the levels of $\mathrm{NO}_{\mathrm{x}}$ were higher (approximately 1-fold) in water than in cell medium, likely owing to the presence of proteins and supplements able to react with NO, thus avoiding its oxidation into nitrites and nitrates. This was, however, in line with data reported by other studies demonstrating that 2 days of light exposure allows SNP to release all the available NO (Rauhala et al., 1998; Wang et al., 2006). Indeed, Fig. 2C shows that, unlike from what was observed with freshly prepared SNP, the concentration of $\mathrm{NO}_{\mathrm{x}}$ measured in the medium of cells treated with the photodegraded SNP did not change significantly during 24-h treatment, demonstrating that the drug was effectively NO exhausted.

Increasing data from the literature demonstrate that nitrite is a bioactive oxidation product of $\mathrm{NO}$ able to elicit physiopathological effects both in in vivo and in in vitro systems (Wink et al., 2001; Cosby et al., 2003). We then evaluated whether $\mathrm{NO}_{\mathrm{x}}$, mainly nitrites generated by SNP under light exposure, could be involved in the cell death process. To evaluate this possibility, we cotreated the cells for $24 \mathrm{~h}$ with $\mathrm{SNP}$ or $\mathrm{SNP}_{\mathrm{ex}}$ along with the nitrite scavenger AMS, and we analyzed cytofluorimetrically the apoptotic extent. Figure 2D shows that treatment of cells with AMS did not protect cells from SNP- or $\mathrm{SNP}_{\mathrm{ex}}$-induced apoptosis, demonstrating that nitrites are not involved in the apoptotic commitment.

Overall, the results clearly demonstrate that neither the 
NO moiety nor NO bioactive degradation product nitrite affect cell viability in SH-SY5Y, suggesting that other molecule(s) could be responsible for apoptotic induction elicited by SNP treatment.

We analyzed whether the vulnerability of SH-SY5Y cells toward SNP was a feature shared with other neuronal cell lines. Therefore, we selected two cell lines known to be sensitive to NO toxicity such as the murine motor neuron $\times$ neuroblastoma hybrid NSC34 and the rat phaeochromocytoma PC12. We treated the cells with different concentra- tions of the freshly prepared or light-exhausted SNP and measured cytofluorimetrically the extent of apoptosis. Figure 2E shows that PC12 and NSC34 cells displayed a higher degree of sensitivity toward SNP toxicity with respect to SH-SY5Y, but they are equally sensitive to both fresh and photodegraded SNP.

Besides the generation of NO and its derived metabolites, solubilization of SNP leads to the production of free cyanide $\left(\mathrm{CN}^{-}\right)$(Friederich and Butterworth, 1995) that could, at least in part, account for apoptosis induction (Mills et al., 1996;
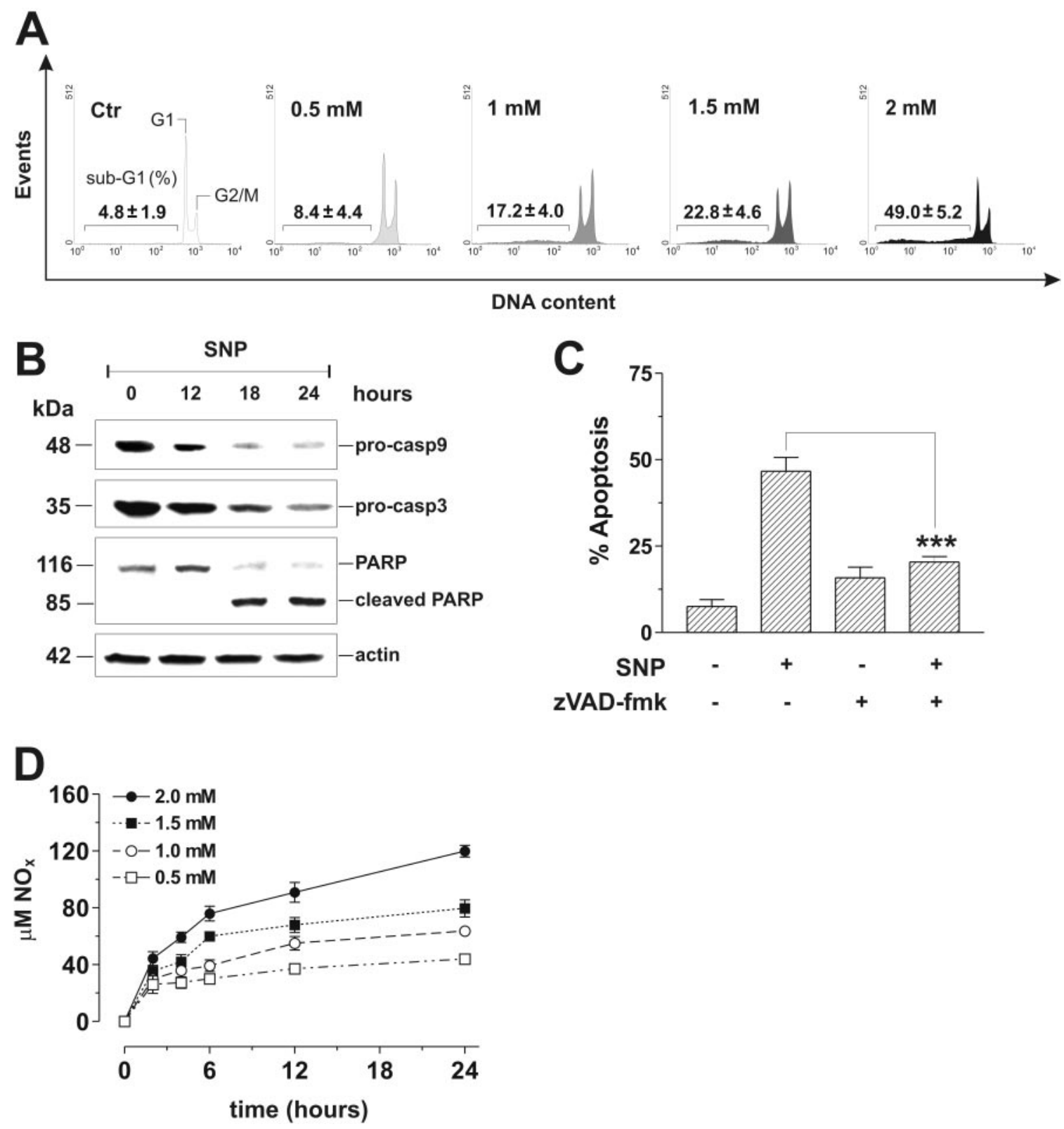

Fig. 1. SNP induces caspase-dependent apoptosis in SH-SY5Y cells. A, SH-SY5Y cells were treated with SNP ranging from 0.5 to $2 \mathrm{mM}$ for $24 \mathrm{~h}$, washed, and stained with propidium iodide. Analysis of sub- $\mathrm{G}_{1}$ (apoptotic) cells was performed by a flow cytometer (FACSCalibur), and percentages of stining-positive cells were calculated using WinMDI version 2.8 software (The Scripps Institute, La Jolla, CA). Data are expressed as percentage of apoptotic cells and represent the mean \pm S.D. of $n=10$ independent experiments. All values are significantly different with respect to control (Ctr). B, SH-SY5Y cells were treated with $2 \mathrm{mM}$ SNP for different times. Then, $50 \mu \mathrm{g}$ of total protein extract was loaded onto each lane for detection of procaspase-9, procaspase-3, and PARP. Actin was used as loading control. Western blots are from one experiment representative of three that gave similar results. C, SH-SY5Y cells were pretreated for $1 \mathrm{~h}$ with or without $20 \mu \mathrm{M}$ pan-caspase inhibitor zVAD-fmk, and then they were treated with $2 \mathrm{mM}$ SNP for $24 \mathrm{~h}$ and analyzed for apoptosis extent. Data are expressed as percentage of apoptotic cells and represent the mean \pm S.D. of $n=4$ independent experiments. ***, $p<0.001$. D, SH-SY5Y cells were treated with SNP ranging from 0.5 to $2 \mathrm{mM}$ up to $24 \mathrm{~h}$. At each time, $100 \mu \mathrm{l}$ of cell media was harvested and spectrophotometrically analyzed for $\mathrm{NO}_{\mathrm{x}}$ content by Griess assay. Data are expressed as micromolar $\mathrm{NO}_{\mathrm{x}}$ and represent the mean \pm S.D. of $n=8$ independent experiments. 
Shou et al., 2003). To exclude the possibility that $\mathrm{CN}^{-}$contributed to SNP cytotoxicity, we monitored mitochondria integrity by labeling these organelles with the transmembrane potential-sensitive probe MitoTracker Red. Results obtained (see Supplemental Fig. 1) demonstrate that mitochondria of cells treated for $12 \mathrm{~h}$ with SNP were unaffected by SNP.
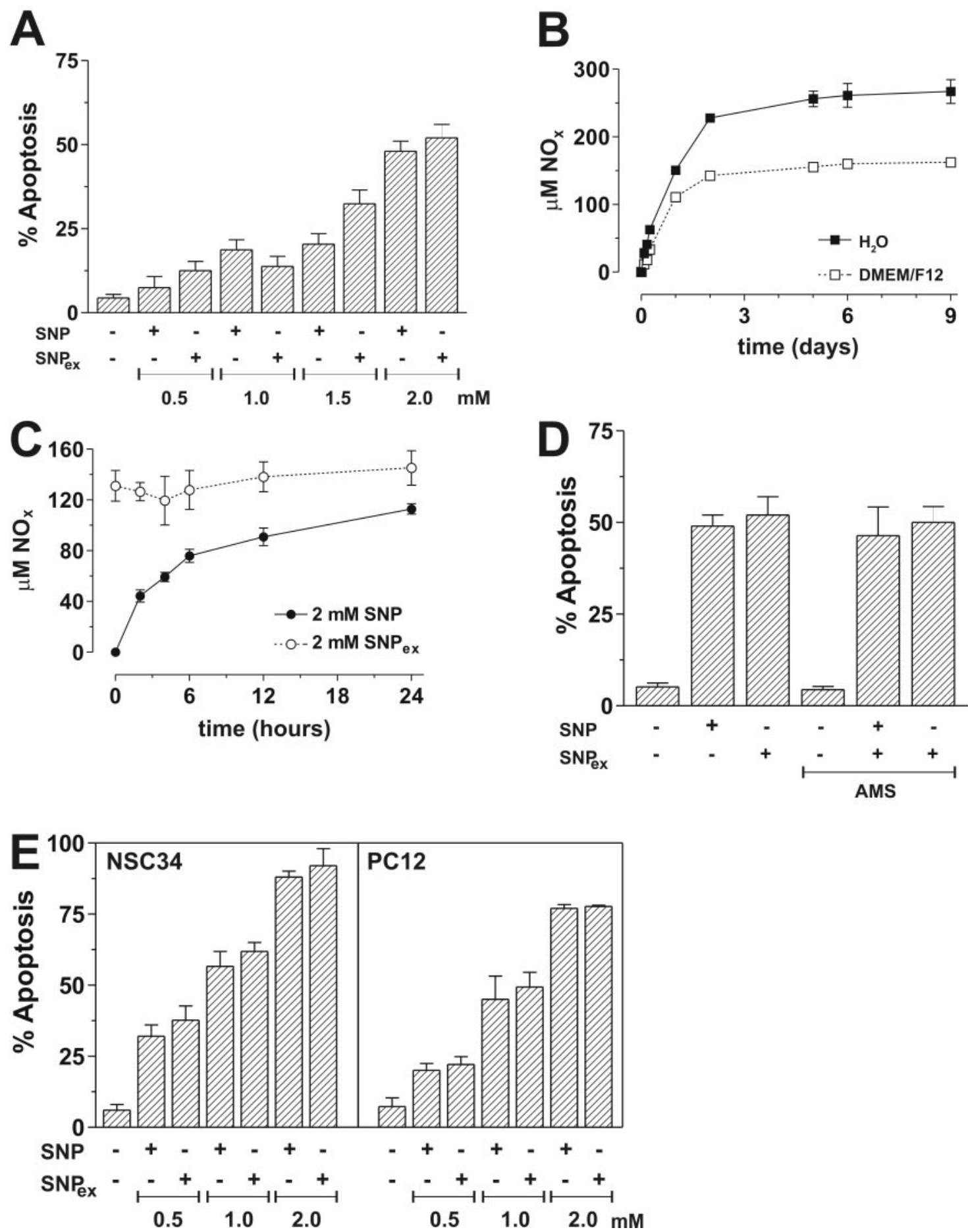

Fig. 2. SNP-induced neuroblastoma apoptosis is independent of $\mathrm{NO}$ and $\mathrm{NO}_{\mathrm{x}}$ production. A, SH-SY5Y cells were treated for $24 \mathrm{~h}$ with different concentrations of SNP or with equimolar amounts of 2-day light-degraded SNP (SNP $\left.{ }_{\mathrm{ex}}\right)$, and analyzed for apoptosis extent. Data are expressed as percentage of apoptotic cells and represent the mean \pm S.D. of $n=4$ independent experiments. All values are significantly different with respect to control. B, 2 mM SNP was dissolved in water or cell medium (DMEM/F-12) up to 9 days. The concentration of $\mathrm{NO}_{x}$ produced by SNP was measured by Griess assay. Data are expressed as micromolar $\mathrm{NO}_{\mathrm{x}}$ and represent the mean \pm S.D. of $n=3$ independent experiments. C, SH-SY5Y cells were treated with $2 \mathrm{mM}$ SNP or SNP ${ }_{\mathrm{e}}$ up to $24 \mathrm{~h}$. At each time, $100 \mu \mathrm{l}$ of cell media was harvested, and the concentration of $\mathrm{NO}_{\mathrm{x}}$ was measured by Griess assay. Data are expressed as micromolar $\mathrm{NO}_{\mathrm{x}}$ and represent the mean \pm S.D. of $n=3$ independent experiments. D, SH-SY5Y cells were treated for $24 \mathrm{~h}$ with $2 \mathrm{mM} \mathrm{SNP}$ or SNP with or without $10 \mathrm{mM}$ AMS and analyzed for apoptosis extent. Data are expressed as percentage of apoptotic cells and represent the mean \pm S.D. of $n=4$ independent experiments. All values are significantly different with respect to control. E, NSC34 and PC12 cells were treated for $24 \mathrm{~h}$ with different concentrations of $\mathrm{SNP}$, or with equimolar amounts of $\mathrm{SNP}_{\mathrm{ex}}$, and analyzed for apoptosis extent. Data are expressed as percentage of apoptotic cells and represent the mean \pm S.D. of $n=4$ independent experiments. All values are significantly different with respect to control. 
Moreover, incubation with thiosulfate, the substrate used by rhodanese in $\mathrm{CN}^{-}$detoxification, did not decrease apoptosis extent (see Supplemental Fig. 1), indicating that free $\mathrm{CN}^{-}$ has not a primary role in SNP-mediated cytotoxicity.

ROS Produced by SNP Are Responsible for SH-SY5Y Cell Death. To dissect the NO-independent mechanism(s) underlying SNP-mediated cell death, we focused on the capability of SNP to induce oxidative stress. Indeed, it has been demonstrated that both during its redox cycling ( $\mathrm{Ra}$ makrishna Rao and Cederbaum, 1996) and after NO release (Rauhala et al., 1998), SNP is able to trigger the generation of ROS, mainly hydroxyl radical $\left(\mathrm{OH}^{*}\right)$ via Fenton reaction. On the basis of these data, we measured cytofluorimetrically ROS content by incubating the cells with the ROS-sensitive fluorochrome DHDCF-DA. Figure 3A shows that ROS were efficiently and time-dependently produced already at $3 \mathrm{~h}$ of SNP treatment. These results prompted us to analyze the content of the tripeptide glutathione, the main and the most abundant low-molecular-weight antioxidant in the cell, by monitoring the alterations in the concentration of both its reduced (GSH) and oxidized (GSSG) forms. High-performance liquid chromatography analyses show that GSH decreased at $3 \mathrm{~h}$ from SNP addition to rise time-dependently up to $12 \mathrm{~h}$ $(+64.3 \pm 1.2 \%)$ (Fig. 3B). GSSG increased during treatment and accumulated within the cells, whereas no detectable changes in the concentration of mixed disulfides between proteins and GSH ( $S$-glutathionylated proteins) could be evidenced (data not shown). Conversely, the amount of carbonylated proteins rose in a time-dependent manner (Fig. 3C), mirroring the kinetics of ROS and GSSG production, indicating that a sustained oxidative stress takes place upon SNP treatment. Because a sustained exposure to ROS could induce DNA damage, resulting in double-strand ruptures, we then monitored whether SNP treatment could affect DNA integrity. We analyzed the phosphoactivation of the DNA double-strand breaksensitive histone H2A.X by fluorescence microscopy. Figure 3D shows that SNP treatment resulted in the appearance of discrete nuclear foci at $6 \mathrm{~h}$, which increased significantly after $12 \mathrm{~h}$. The pictures indicate the recruiting sites of the DNA repair machinery and revealed DNA-specific damage was occurring, also in this case in a time-dependent manner. Moreover, because SNP is an iron-nitrosyl complex and iron is a redox-active metal that represents an excellent catalyst of redox cycles, we determined intracellular iron accumulation by means of atomic absorption spectroscopy. Figure $3 \mathrm{E}$ shows that iron accumulated intracellularly in a time-dependent manner, reaching values close to $3 \mathrm{nmol}$ of iron per milligram of protein at $12 \mathrm{~h}$ of treatment, values similar to those obtained upon treatment with SNPex (data not shown). We then performed experiments with DEF, a well known iron chelator, and we cytofluorometrically analyzed ROS content and apoptosis. Cells incubated for $3 \mathrm{~h}$ with $\mathrm{SNP}$ or $\mathrm{SNP}_{\mathrm{ex}}$ in the presence of DEF showed a significant decrease of ROS concentration to values similar to untreated cells (Fig. 3F). This result correlated well with the percentage of apoptotic cells measured after 24 of treatment with $\mathrm{SNP}$ or $\mathrm{SNP}_{\mathrm{ex}}$ (Fig. 3F), confirming the role of iron as principal ROS generator under our conditions. To establish the role of ROS as functional mediator of SNP-, as well as of $\mathrm{SNP}_{\mathrm{ex}}$-induced apoptosis, we tested the effect of several antioxidants and ROS scavengers on SH-SY5Y viability. Incubation of the cells with specific $\mathrm{OH}^{*}$ radical scavengers such as DMTU, DMSO, and TEMPOL resulted in a significant protec- tion against SNP- and $\mathrm{SNP}_{\mathrm{ex}}$-induced apoptosis (Fig. 4A). By contrast, no significant recovery of cell viability was achieved by treating the cells with superoxide dismutase or catalase, enzymes catalyzing the scavenging of superoxide and hydrogen peroxide, respectively (data not shown). To verify the effective antioxidant ability of DMTU, DMSO, and TEMPOL, we measured ROS production during their incubation along with SNP and $\mathrm{SNP}_{\mathrm{ex}}$. Consistent with the recovery of cell viability, these radical scavengers reduced ROS concentration (Fig. 4B). These overall data demonstrate that ROS represent the molecular inducers of SNP cytotoxicity, suggesting that $\mathrm{OH}^{*}$ is probably the oxy-radical principally involved in the apoptotic induction.

Involvement of p53 in SNP Cytotoxicity. To dissect the signaling pathway(s) involved in SNP-induced apoptosis, we focused on p53, a transcription factor activated by several stress conditions such as redox unbalance and DNA damage. Figure 4C shows Western blot analyses of p53 upon treatment with either $\mathrm{SNP}$ or $\mathrm{SNP}_{\mathrm{ex}}$, evidencing an induction of the protein starting as early as $6 \mathrm{~h}$ of treatment to reach the highest levels after $12 \mathrm{~h}$. It is noteworthy that besides an enhancement of the total immunoreactivity band of p53, an increase of the high-molecular-weight band, reasonably representing the hyperphosphorylated/activated form of the protein (Filomeni et al., 2007), could be observed upon both treatments. To confirm p53 activation, we monitored the levels of the cyclin-dependent kinase inhibitor p21, as well as Bax, two of the well established target genes of p53, deputed to cell cycle arrest and apoptosis commitment, respectively. As depicted by Fig. 4C, p21 and Bax are up-regulated after $6 \mathrm{~h}$ of treatment, suggesting that accumulation of p53 is followed by the acquisition of its nuclear transacting properties. To exclude the possibility that nitrite, could account for p53 activation, we cotreated the cells for $12 \mathrm{~h}$ with SNP or $\mathrm{SNP}_{\mathrm{ex}}$ and AMS. Figure 4D shows that AMS did not affect p53 activation elicited by SNP or $\mathrm{SNP}_{\mathrm{ex}}$ treatment, confirming that nitrite is not involved in the activation of p53 tumor suppressor protein.

To establish the role of p53 in the apoptosis induction, we transfected SH-SY5Y cells with an siRNA against p53 (sip53) or with a scramble sequence that does not share homology with any other human mRNAs (siScr). Cytofluorimetric analyses showed that the percentage of apoptotic cells was significantly reduced upon p53 interference in both SNP- and $\mathrm{SNP}_{\mathrm{ex}}$-treated cells (Fig. 4E), demonstrating that p53, activated in response to cell damage, contributes to the apoptotic commitment. In line with such results, Western blot analyses depicted in Fig. 4F show that p53 and its downstream targets Bax and p21 were only slightly induced upon 6 and $12 \mathrm{~h}$ of treatment with $\mathrm{SNP}$ and $\mathrm{SNP}_{\text {ex }}$ in sip53 cells, with respect to siScr counterparts.

Data presented so far demonstrated that SNP treatment was able to produce sustained oxidative stress and cellular damage that culminated in cell death and elicited p53 activation regardless NO production. Nevertheless, a direct link between ROS production and p53 induction was not pointed out yet. Therefore, to directly examine the role of ROS in p53 activation, we treated SH-SY5Y cells with DMTU, DMSO, and TEMPOL along with SNP or $\mathrm{SNP}_{\text {ex }}$. Figure 5A shows that, similarly to the recovery of cell viability (Fig. 4A) and scavenge of ROS (Fig. 4B), DMTU, DMSO, and TEMPOL reduced p53, p21, and Bax accumulation after $12 \mathrm{~h}$ of treatment, demonstrating that in our experimental system, p53 
A
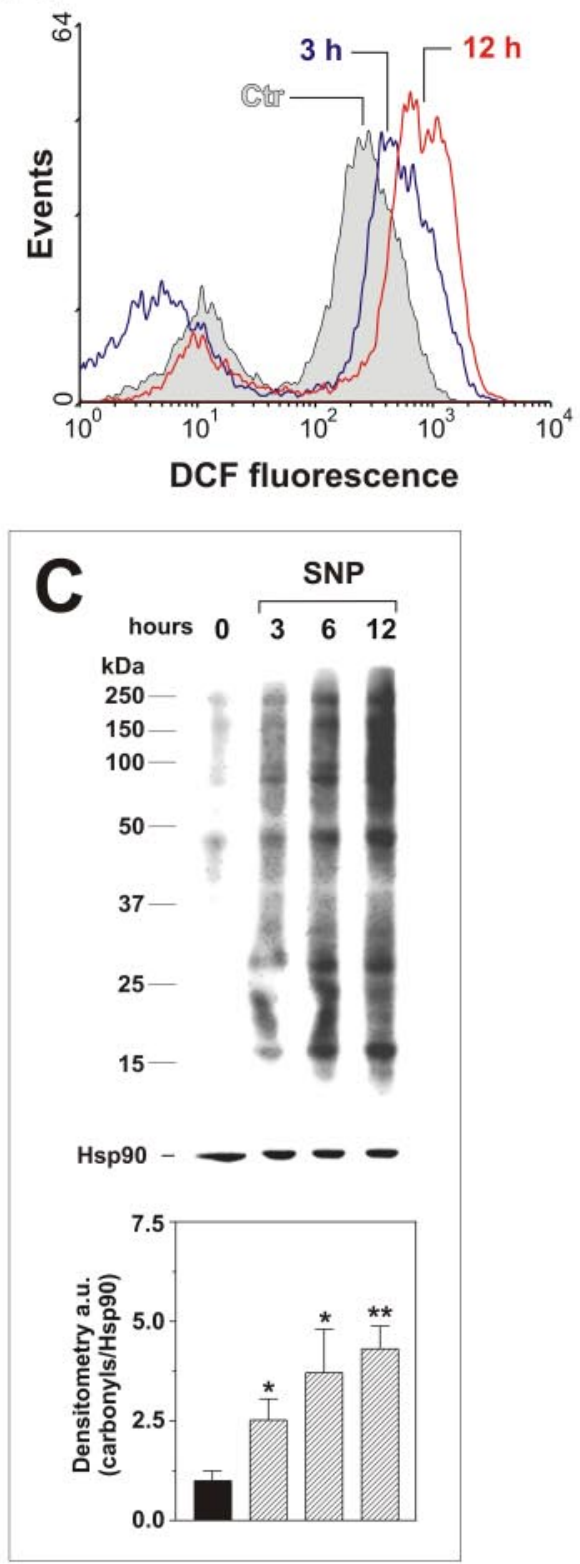

E

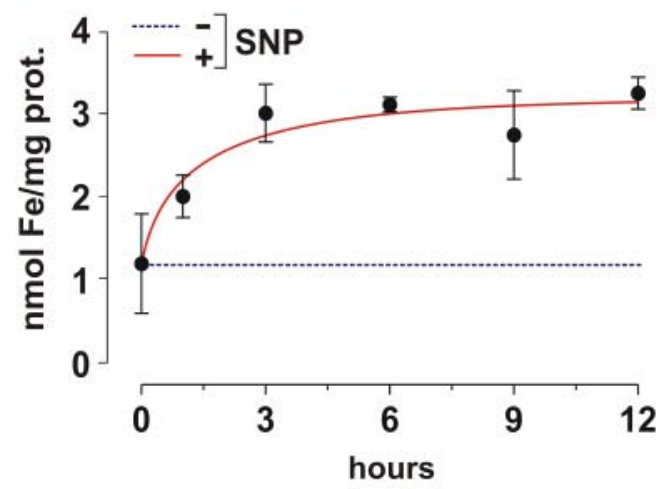

D
B

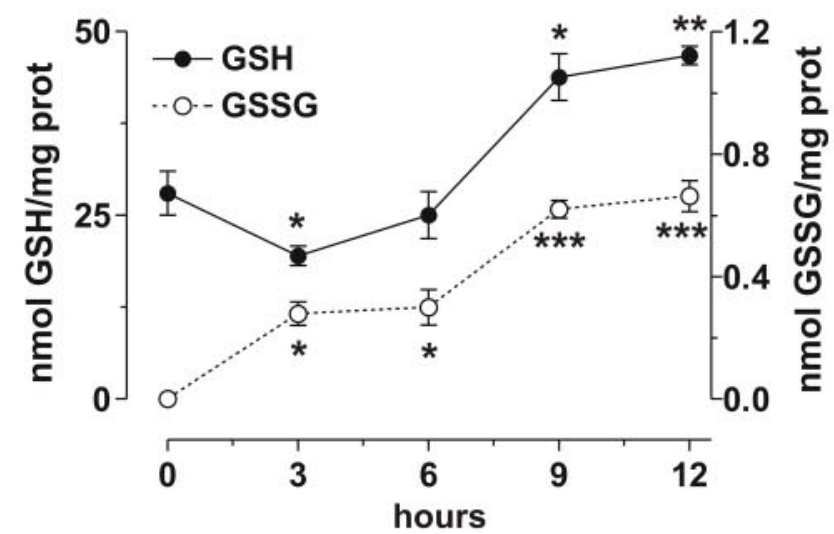

SNP
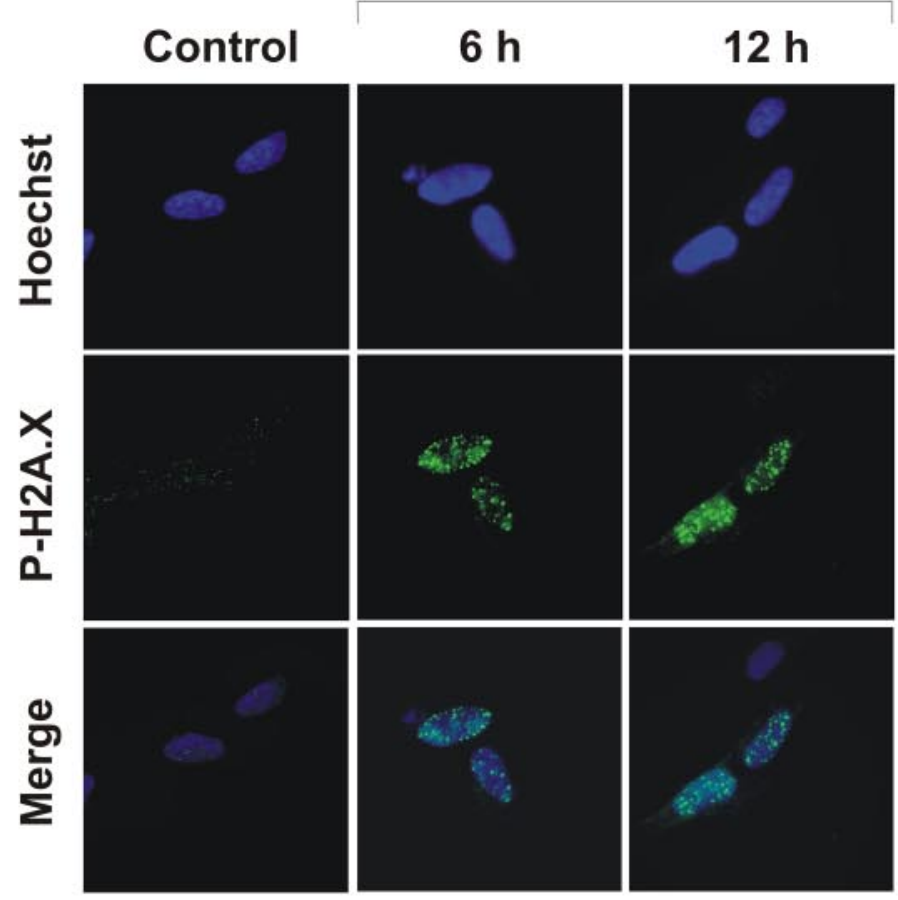

F

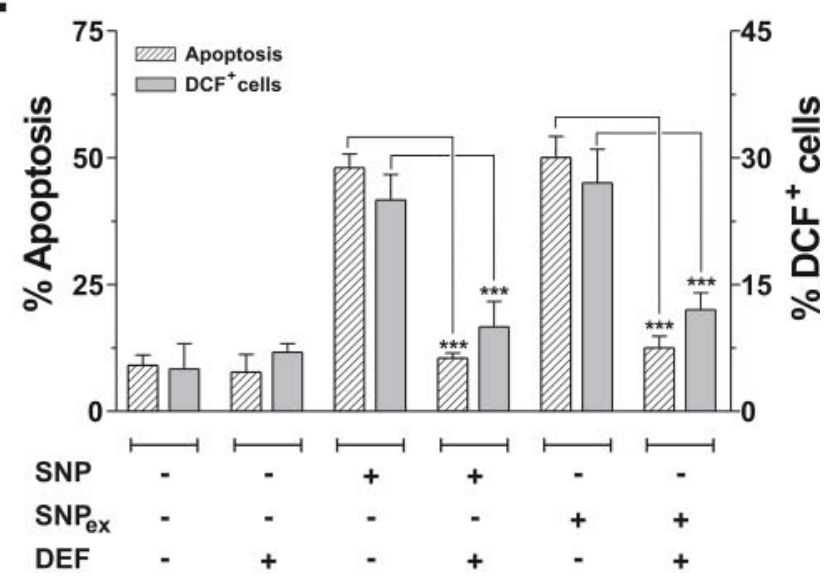

Fig. 3. SNP-induced ROS production correlates with intracellular iron uptake and oxidative damage to proteins and DNA. A, SH-SY5Y cells were treated with $2 \mathrm{mM}$ SNP for different times and cytofluorimetrically analyzed for intracellular ROS content by coincubation with $50 \mu \mathrm{M}$ DCFH-DA. 
activation was a ROS-dependent event. Moreover, thiosulfate incubation did not affect p53 induction (see Supplemental Fig. 1), confirming that $\mathrm{CN}^{-}$did not contribute to SNP proapoptotic activity. The functional connection among ROS, nuclear damage, and p53 activation was further revealed by means of fluorescence microscopy. As depicted in Fig. 5B, DMTU, DMSO, and TEMPOL were able to reduce the phosphoactivation levels of the histone H2A.X after $12 \mathrm{~h}$ of treatment with SNP, as well as p53 nuclear localization (Fig. 5B), providing a link between oxidative stress, DNA damage, and the engagement of p53-mediated signaling pathway.

Ferricyanide Is Unable to Reproduce SNP-Mediated Toxic Effects. To further validate the primary role played by ROS in SNP-induced p53 activation and apoptosis, we treated $\mathrm{SH}-\mathrm{SY} 5 \mathrm{Y}$ cells with $\mathrm{Fe}(\mathrm{CN})_{6}$, the structurally closest and most stable analog of SNP, often used as its sham control. Lacking of any $\mathrm{NO}$ moiety, $\mathrm{Fe}(\mathrm{CN})_{6}$ is unable to produce $\mathrm{NO}$, but differently from $\mathrm{SNP}_{\mathrm{ex}}$, it is a redox-steady molecule. In fact, as shown in Fig. 6A, treatment with $\mathrm{Fe}(\mathrm{CN})_{6}$ did not increase intracellular ROS concentration, even after $12 \mathrm{~h}$ of treatment, confirming the different redox nature of $\mathrm{SNP}_{\mathrm{ex}}$ and $\mathrm{Fe}(\mathrm{CN})_{6}$, with the former able to catalyze ROS production and the latter completely inert. Consistent with this feature, $\mathrm{Fe}(\mathrm{CN})_{6}$ was able to affect neither $\mathrm{SH}-\mathrm{SY} 5 \mathrm{Y}$ cell viability (Fig. 6B) nor induction of p53 up-regulation (Fig. 6C), providing further evidence that SNP-induced cell death and p53 activation are two phenomena elicited by a ROSmediated insult.

ROS-Resistant Cells Are Insensitive to SNP-Induced Cell Damage and Apoptosis. To further investigate the role of oxidative stress as the main mediator in SNP-induced apoptosis and p53 activation, we selected the gastric adenocarcinoma AGS, a cell line known to be particularly resistant to ROS-mediated damage and death by means of its efficient antioxidant systems, mainly associated with GSH and its related enzymes (Filomeni et al., 2005). Figure 7A shows histograms from analyses of apoptotic cells, indicating that AGS cells did not undergo cell death upon $24 \mathrm{~h}$ of treatment with $2 \mathrm{mM}$ SNP, although the amount of $\mathrm{NO}_{\mathrm{x}}$ generated was comparable between the two cell lines (142.30 \pm 25.12 versus $119.90 \pm 4.20$ in AGS and SH-SY5Y, respectively). Moreover, SNP treatment elicited neither a significant increase of protein carbonyls (Fig. 7B) nor appreciable DNA damage (Fig. 7C). Consistent with these observations, no p53 up-regulation was observed up to $12 \mathrm{~h}$ of SNP treatment (Fig. 7D), confirming the hypothesis that SNP toxicity and p53 activation are directly linked to cellular sensitivity to oxidative stress.

\section{Discussion}

This study demonstrates that ROS, rather than NO, are the genuine mediators of apoptosis elicited upon SNP exposure in SH-SY5Y cells, in line with growing evidence showing other effectors of SNP bioactivity. In fact, no difference was observed in the apoptotic cell percentage between freshly prepared and $\mathrm{SNP}_{\mathrm{ex}}$, which is devoid of NO. SNP exhaustion can be triggered by light exposure, as well as by reductive processes carried out in an enzymatic or thiol-mediated manner (Rao et al., 1991; Mohazzab-H et al., 1999; Grossi and D'Angelo, 2005) during which the nitroprusside nitroxide radical anion undergoes redox cycling to generate hydroxyl radical $\left(\mathrm{OH}^{*}\right)$ (Ramakrishna Rao and Cederbaum, 1996). Moreover, Rauhala et al. (1998) demonstrated that the ability of SNP to generate ROS is further maintained after the complete release of $\mathrm{NO}$ by means of the free iron coordination site for $\mathrm{H}_{2} \mathrm{O}_{2}$ that can lead to the generation of $\mathrm{OH}^{\cdot}$ via the Fenton reaction. In line with these observations, we demonstrate the occurrence of an oxidative stress and cellular oxidative damage during both $\mathrm{SNP}$ and $\mathrm{SNP}_{\mathrm{ex}}$ exposure in $\mathrm{SH}$ SY5Y cells. Although an indirect ROS production was already pointed out in several papers describing proapoptotic properties of NO donors (Pacher et al., 2007), the pro-oxidant action of SNP seems to be an intrinsic characteristic of this molecule. In fact, whereas NO and RNS can increase intracellular ROS content [e.g., by inhibiting components of the mitochondrial respiratory chain (Schild et al., 2003)], we found that SNP is able to directly induce apoptosis and to generate ROS proportionally to its concentration (data not shown) and independently of mitochondria impairment. Moreover, the recovery of cell viability and the consistent attenuation of ROS formation, obtained using radical scavengers relatively specific for $\mathrm{OH}^{*}$, demonstrate that ROS, generated upon SNP decomposition, could be the genuine mediators of its cytotoxicity. Moreover, the ineffectiveness of superoxide dismutase and catalase in decreasing SNP toxicity supports the hypothesis that $\mathrm{OH}^{*}$ is reasonably the main oxy-radical involved in the induction of apoptosis.

The pivotal role played by ROS in SNP cytotoxicity was also confirmed by the experiments carried out with $\mathrm{Fe}(\mathrm{CN})_{6}$. This compound is structurally the closest analog of SNP, in which the NO moiety is replaced by another cyanide group; but, notwithstanding their structural similarity, they exhibit different stability and reactivity remaining distinct iron-containing molecules, with $\mathrm{Fe}(\mathrm{CN})_{6}$ being a ROS unproductive molecule. These properties can reasonably explain the different effects observed on SH-SY5Y cells viability, where

Cytofluorimetric histograms are from one experiment of five that gave similar results. B, SH-SY5Y cells were treated with $2 \mathrm{mM}$ SNP for different times and analyzed for intracellular levels of reduced (GSH) and oxidized (GSSG) forms of glutathione by high-performance liquid chromatography. Data are expressed as nanomoles of GSH or GSSG per milligram of total proteins and represent the mean \pm S.D. of $n=6$ independent experiments. $*, p<0.05 ; * *, p<0.01 ; * * *, p<0.001$. C, SH-SY5Y cells were treated with $2 \mathrm{mM}$ SNP for different times. Then, $40 \mu \mathrm{g}$ of total protein extract was reacted with DNP, resolved on 10\% SDS-PAGE, and DNP-derivatized proteins were identified by Western blot using an anti-DNP antibody. Hsp90 was used as loading control, and densitometry of each lane (bottom) was calculated using Quantity One software (Bio-Rad) (black bars, control; striped bars, SNP-treated). Data are expressed as arbitrary units (a.u.) with respect to Hsp90 and represent the mean \pm S.D. of $n=4$ independent experiments. *, $p<0.05 ; * *, p<0.01$. D, SH-SY5Y cells, treated with $2 \mathrm{mM}$ SNP for 6 and $12 \mathrm{~h}$, were used for immunofluorescence analysis of the phosphoactive (Ser-139) isoform of double-strand break-sensitive histone H2A.X (P-H2A.X). Nuclear foci (green) represent the recruitment of DNA repair machinery. Staining with Hoechst 33342 (blue) was performed to evidence nuclei of the cells. E, SH-SY5Y cells were treated with 2 mM SNP up to $12 \mathrm{~h}$ and analyzed for intracellular iron concentration by atomic absorption spectrometry. Data are expressed as nanomoles of iron per milligram of total proteins and represent the mean \pm S.D. of $n=9$ independent experiments. All values are significantly different with respect to control, except

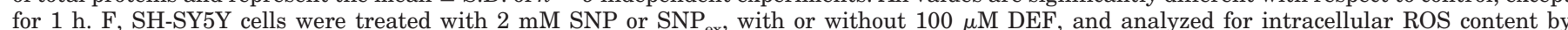
coincubation with $50 \mu \mathrm{M}$ DCFH-DA (at $3 \mathrm{~h}$ ), or alternatively, for apoptosis extent, upon staining with propidium iodide (after $24 \mathrm{~h}$ ). Data are expressed as percentage of DCF-positive or apoptotic cells, respectively, and represent the mean \pm S.D. of $n=4$ independent experiments. $* * *, p<0.001$. 
$\mathrm{Fe}(\mathrm{CN})_{6}$ was not toxic. Moreover, these results strengthen the role played by ROS in SNP-induced apoptosis; and, at the same time, as suggested previously in other reports (Rauhala et al., 1998; Wang et al., 2006), indicate in $\mathrm{SNP}_{\text {ex }}$ a more suitable control compound to assess the molecular effectiveness of SNP bioactivity, with respect to $\mathrm{Fe}(\mathrm{CN})_{6}$. The involvement of ROS in cell demise supports the hypothesis that p53 could be activated in response to ROS-dependent nuclear

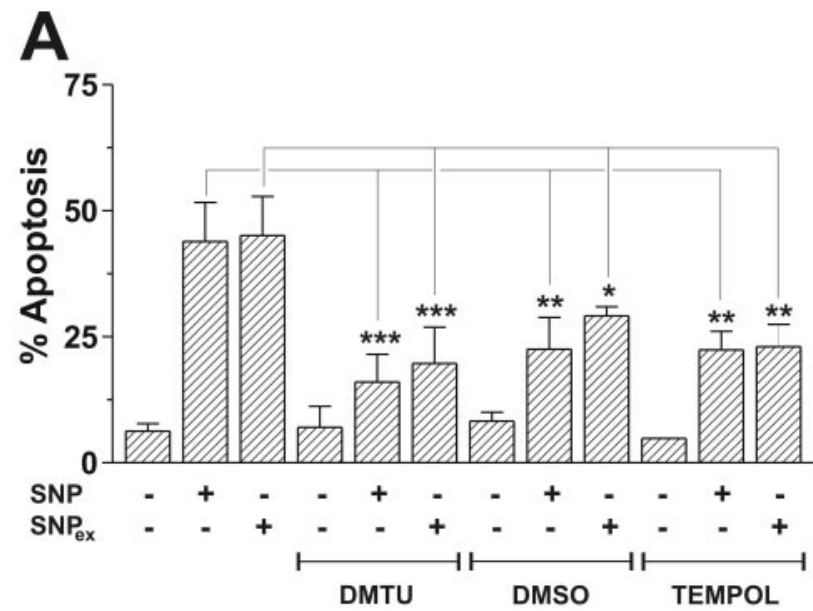

B

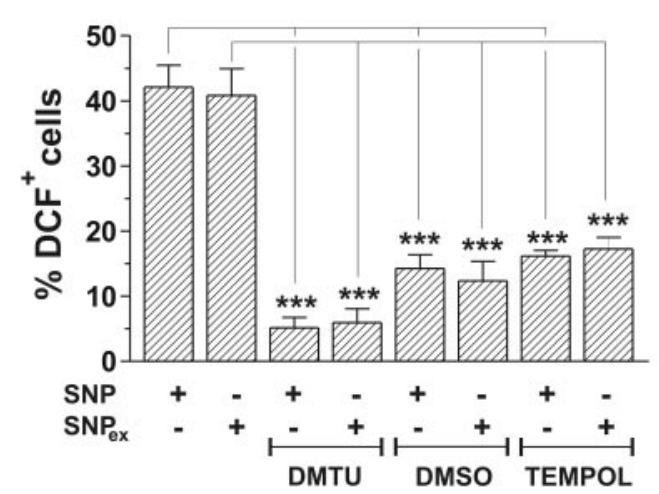

C

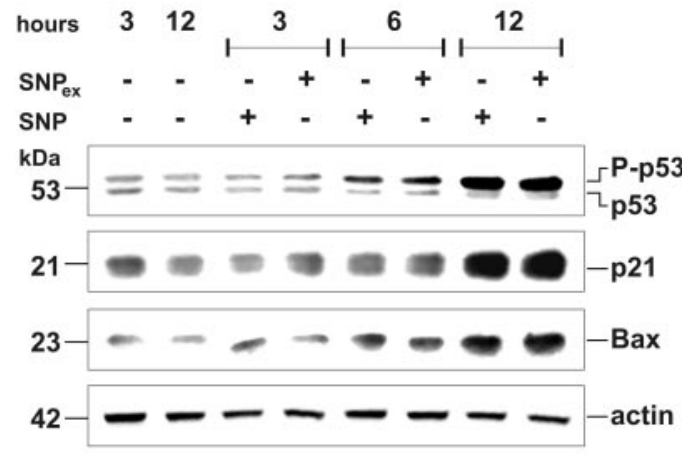

D
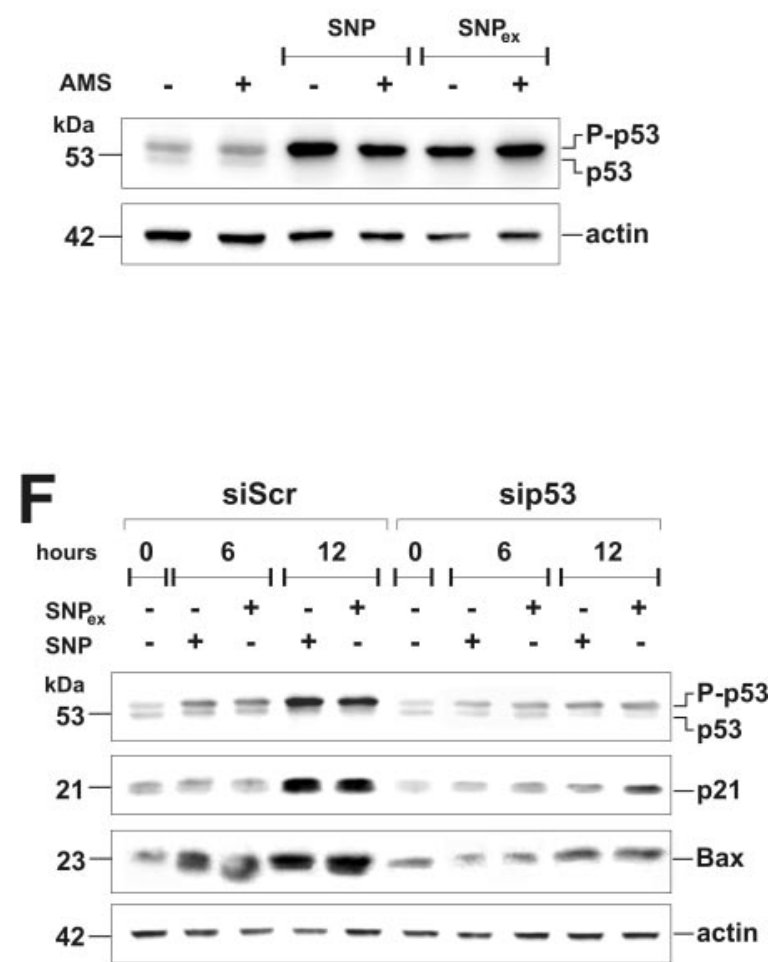

Fig. 4. SNP-induced apoptosis is an ROS-dependent and p53-associated event. A, SH-SY5Y cells were treated for $24 \mathrm{~h}$ with $2 \mathrm{mM}$ SNP or 2-day light-degraded SNP $\left(\mathrm{SNP}_{\mathrm{ex}}\right)$, with or without $20 \mathrm{mM}$ DMTU, or $3 \mu \mathrm{M}$ DMSO, or $1.5 \mu \mathrm{M}$ TEMPOL, and analyzed for apoptosis extent. Data are expressed as percentage of apoptotic cells and represent the mean \pm S.D. of $n=4$ independent experiments. $*, p<0.05 ; * *, p<0.01 ; * * *, p<0.001$. $\mathrm{B}$, SH-SY5Y cells were treated for $24 \mathrm{~h}$ with $2 \mathrm{mM} \mathrm{SNP}$ or SNP, with or without $20 \mathrm{mM}$ DMTU, or $3 \mu \mathrm{M}$ DMSO, or $1.5 \mu \mathrm{M}$ TEMPOL and cytofluorimetrically analyzed for intracellular ROS content by coincubation with $50 \mu \mathrm{M}$ DCFH-DA. Data are expressed as percentage of DCF-positive cells and represent the mean \pm S.D. of $n=3$ independent experiments. $* * *, p<0.001$. C, SH-SY5Y cells were treated with $2 \mathrm{mM}$ SNP or SNP for $_{\text {ex }}$ different times. Then, $50 \mu \mathrm{g}$ of total protein extract was loaded onto each lane for detection of p53, p21, and Bax. Actin was used as loading control. Western blots are from one experiment representative of three that gave similar results. P-p53, phosphorylated p53. D, SH-SY5Y cells were treated for $12 \mathrm{~h}$ with $2 \mathrm{mM}$ SNP or SNP with or without $10 \mathrm{mM}$ AMS. Then, $50 \mu \mathrm{g}$ of total protein extract was loaded onto each lane for detection of p53. Actin was used as loading control. Western blots are from one experiment representative of three that gave similar results. E, SH-SY5Y cells were transiently transfected with siRNA duplex directed against the p53 mRNA target sequence (sip53) or with a scramble siRNA duplex (siScr). Cell adhesion has been allowed for $12 \mathrm{~h}$ (time at which maximum decrease of $\mathrm{p} 53$ was obtained), and then the cells were treated for additional $24 \mathrm{~h}$ with $2 \mathrm{mM}$ SNP or SNP $\mathrm{ex}_{\mathrm{x}}$ and analyzed for apoptosis extent. Data are expressed as percentage of apoptotic cells and represent the mean \pm S.D. of $n=3$ independent experiments. $* *, p<0.01$. F, after $12 \mathrm{~h}$ from cell adhesion, siScr and sip53 cells were treated with $2 \mathrm{mM} \mathrm{SNP}$ or SNP $\mathrm{ex}_{\text {for }}$ different times. Then, $50 \mu \mathrm{g}$ of total protein extract was loaded onto each lane for detection of p53, p21, and Bax. Actin was used as loading control. Western blots are from one experiment representative of three that gave similar results. 
damage and could mediate the induction of apoptosis. p53 is one of the most characterized tumor suppressor proteins that acts in response of different forms of cellular insults, such as hypoxia, DNA damage, and oxidative and nitrosative stress, to mediate a variety of antiproliferative processes, among which is the control of cell cycle and apoptosis (Vousden and Lane, 2007). According to the current view, phosphorylation of p53 at various sites, increases its stabilization and nuclear accumulation in nuclei in which it coordinates different responses to stress signals, by modulating the expression of a wide group of target genes, among which p21 and Bax are two of the best characterized. In response to DNA damage, p53 promotes cell cycle arrest at $\mathrm{G}_{1}$ or $\mathrm{G}_{2}$ phase to allow DNA to be repaired before proceeding into mitosis, by inducing the expression of cyclin-dependent kinases inhibitors such as p21. When the damage is too severe to be repaired, p53 also regulates the expression of several genes (e.g., Bax) able to engage the mitochondrial apoptotic pathway, leading to cell death (Fridman and Lowe, 2003; Yu and Zhang, 2005). In
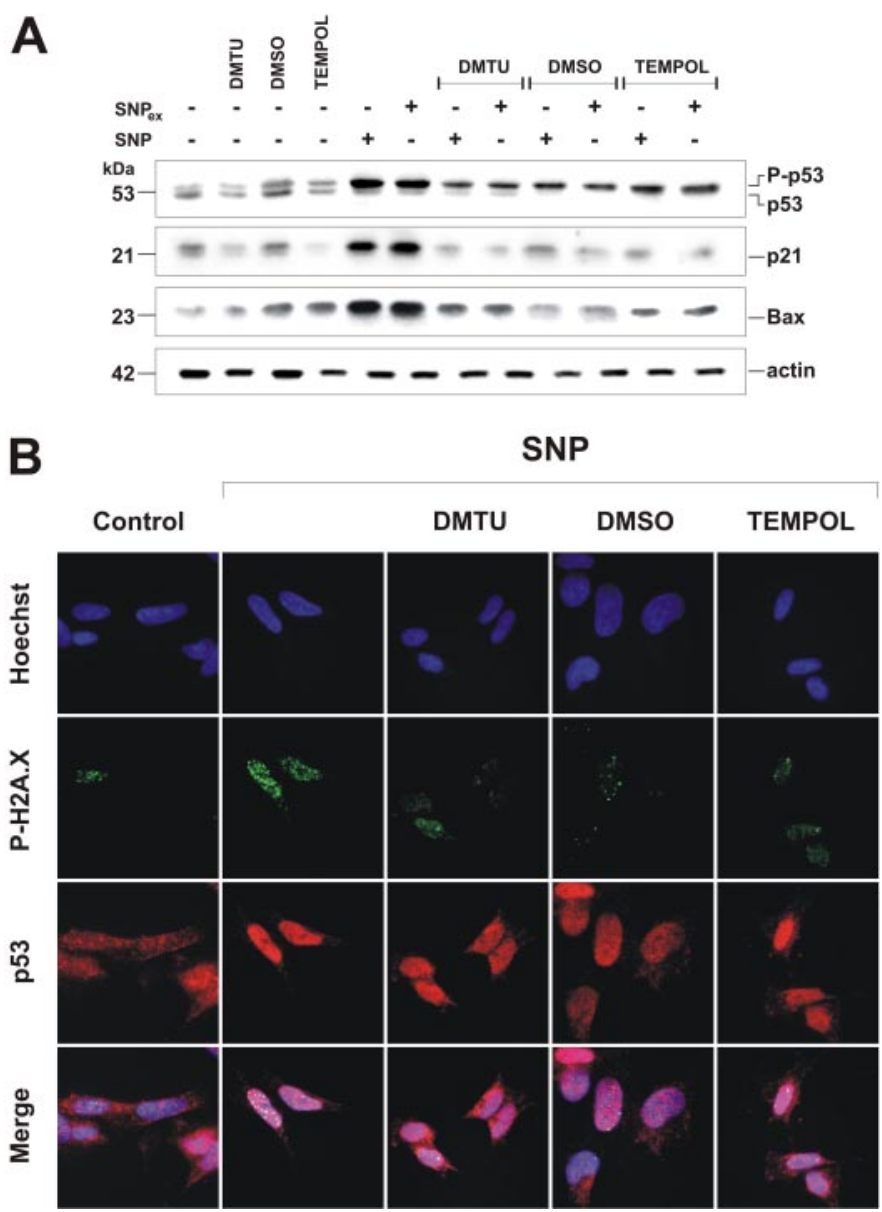

Fig. 5. p53 activation is responsive to SNP-induced ROS production and oxidative damage. A, SH-SY5Y cells were treated for $12 \mathrm{~h}$ with $2 \mathrm{mM}$ SNP or with equimolar amounts of 2-day light-degraded SNP $\left(\mathrm{SNP}_{\mathrm{ex}}\right)$, with or without $20 \mathrm{mM}$ DMTU, or $3 \mu \mathrm{M}$ DMSO, or $1.5 \mu \mathrm{M}$ TEMPOL. Then, $50 \mu \mathrm{g}$ of total protein extract was loaded onto each lane for detection of p53, p21, and Bax. Actin was used as loading control. Western blots are from one experiment representative of three that gave similar results. P-p53, phosphorylated p53. B, SH-SY5Y cells were treated for $12 \mathrm{~h}$ with $2 \mathrm{mM}$ SNP or $\mathrm{SNP}_{\mathrm{ex}}$, with or without $20 \mathrm{mM}$ DMTU, or $3 \mu \mathrm{M}$ DMSO, or $1.5 \mu \mathrm{M}$ TEMPOL. Then, the cells were used for immunofluorescence analysis of the phosphoactive histone H2A.X (P-H2A.X; green) and p53 (red). Staining with Hoechst 33342 (blue) was performed to evidence nuclei of the cells. line with the general understanding of p53 regulation, in the current study we report that SNP treatment is able to trigger p53 phosphoactivation and nuclear accumulation, which denote the acquisition of transcriptional activity as evidenced by the increase of p21 and Bax levels. Whereas up-regulation of p21 is consistent with cell cycle arrest in $\mathrm{G}_{2} / \mathrm{M}$ phase, an event particularly evident with intermediate doses of SNP, Bax induction could be functional to mediate the proapoptotic activity of p53, as demonstrated by the attenuation of the apoptotic extent in experiments performed with p53 siRNA. The engagement of both p53/p21 and p53/Bax signaling pathways seems to be triggered by ROS and/or ROS-mediated damage during SNP treatment; in fact, oxy-radical scavengers attenuate DNA double-strand breaks, p53 activation, and p21/Bax up-regulation as well. The role played by ROS in apoptotic induction and p53 activation finds further confirmation in the different behaviors of neuroblastoma and AGS cells toward SNP toxicity. In previous work, we demonstrated that the gastric adenocarcinoma AGS cells are particularly resistant to ROS-mediated insults by exploiting their efficient GSH-related antioxidant systems (Filomeni et al., 2005). Although the amount of $\mathrm{NO}_{\mathrm{x}}$ generated by SNP was the same in the two cell lines, AGS cells are completely insensitive to SNP-induced cell damage and death, reinforcing the hypothesis that SNP toxicity and p53 activation are two phenomena directly linked to cellular sensitivity to oxidative stress. It has to be pointed out that DNA damage, activation of p53, and p21-mediated cell cycle arrest and Bax up-regulation are believed to play important roles during nitrosative stress and NO-induced apoptosis of various cell types, including SH-SY5Y cells (Ciriolo et al., 2000; Kim et al., 2002; Lee et al., 2006). However, that $\mathrm{SNP}_{\mathrm{ex}}$ was efficient in generating ROS and in increasing p53, p21, and Bax content as much as SNP and that AMS was ineffective in reducing apoptotic degree provide straightforward evidence that neither the NO moiety of SNP nor its derived oxidation by-product nitrite is directly involved in apoptosis induction, under our experimental conditions.

Although the biochemical mechanisms responsible for ROS production upon SNP treatment deserve to be thoroughly investigated, on the basis of literature data and the results obtained here, it is reasonable to suppose an active involvement of iron in oxidative stress induced by SNP. Indeed, atomic absorption spectroscopy showed that upon SNP treatment, iron accumulated intracellularly in a time-dependent manner-a result that parallels ROS increase, oxidative damage, and p53 activation. Therefore, this event could reasonably represent the crucial step for the induction of oxidative stress and lead us to speculate that besides oxy-radicals, high-reactive iron species such as ferryl and perferryl species $\left[\mathrm{Fe}(\mathrm{IV})=\mathrm{O}\right.$ or $\left.\mathrm{FeO}^{2+}\right]$ could form, as suggested in a previous work (Ramakrishna Rao and Cederbaum, 1996), thereby contributing in inducing DNA damage and accounting for SNP cytotoxicity.

Finally, we also demonstrate that upon SNP treatment, cyanide has no role in the establishment of the stress condition leading to p53 activation and cell death. In fact, although SNP contains five cyanide molecules that could promote mitochondrial impairment, our results show that mitochondria of cells treated with SNP are still viable. These results are confirmed by the maintenance of mitochondrial membrane potential, which only evidences the appearance of a small cell 
population at lower potential, which reasonably could be due to activation of the mitochondrial apoptotic pathway. Moreover, incubation of the cells with the highest subtoxic concentration of thiosulfate, the substrate used by rhodanese in cyanide detoxification, does not affect the extent of apoptosis.
Overall, the results obtained in this study indicate that even though SNP represents a good NO donor in in vivo systems, it does not faithfully mimic pathophysiological effects elicited by NO. Therefore, care is needed when interpreting studies on the effects of SNP, because the role of ROS
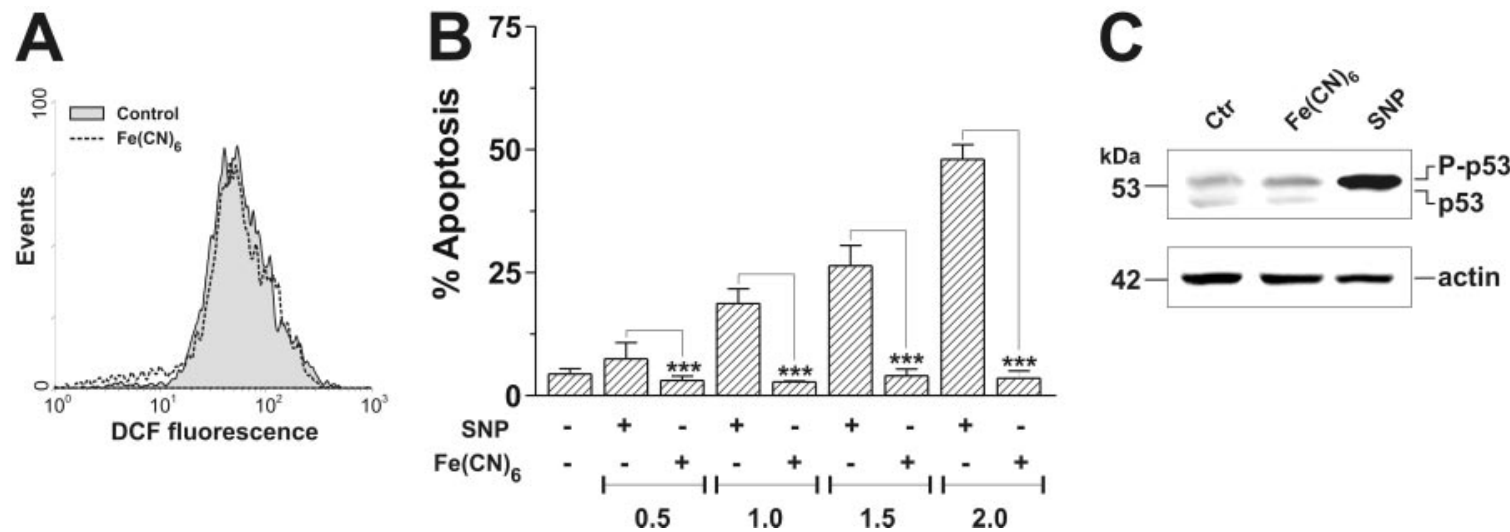

Fig. 6. Ferricyanide does not yield ROS increase, p53 induction, and commitment to cell death. A, SH-SY5Y cells were treated for $12 \mathrm{~h}$ with $2 \mathrm{mM}$ $\mathrm{Fe}(\mathrm{CN})_{6}$ and cytofluorimetrically analyzed for intracellular ROS content by coincubation with $50 \mu \mathrm{M}$ DCFH-DA. Cytofluorimetric histograms are from one experiment of five that gave similar results [dotted line; $\mathrm{Fe}(\mathrm{CN})_{6}$-treated cells]. B, SH-SY5Y cells were treated for $24 \mathrm{~h}$ with $2 \mathrm{mM} \mathrm{Fe}(\mathrm{CN})_{6}$ or SNP and analyzed for apoptosis extent. Data are expressed as percentage of apoptotic cells and represent the mean \pm S.D. of $n=4$ independent experiments. $* * *, p<0.001$. C, SH-SY5Y cells were treated for $12 \mathrm{~h}$ with $2 \mathrm{mM} \mathrm{Fe}(\mathrm{CN})_{6}$ or SNP. Then, $50 \mu \mathrm{g}$ of total protein extract was loaded onto each lane for detection of p53. Actin was used as loading control. Western blots are from one experiment representative of three that gave similar results. P-p53, phosphorylated p53.
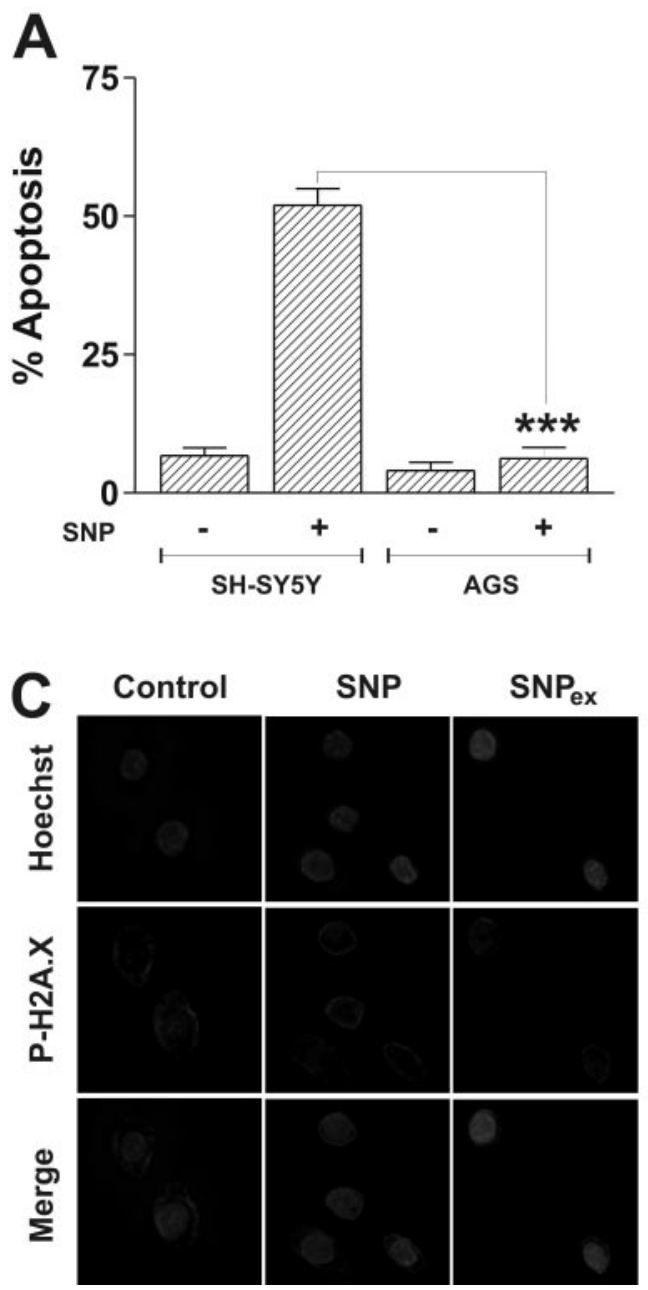
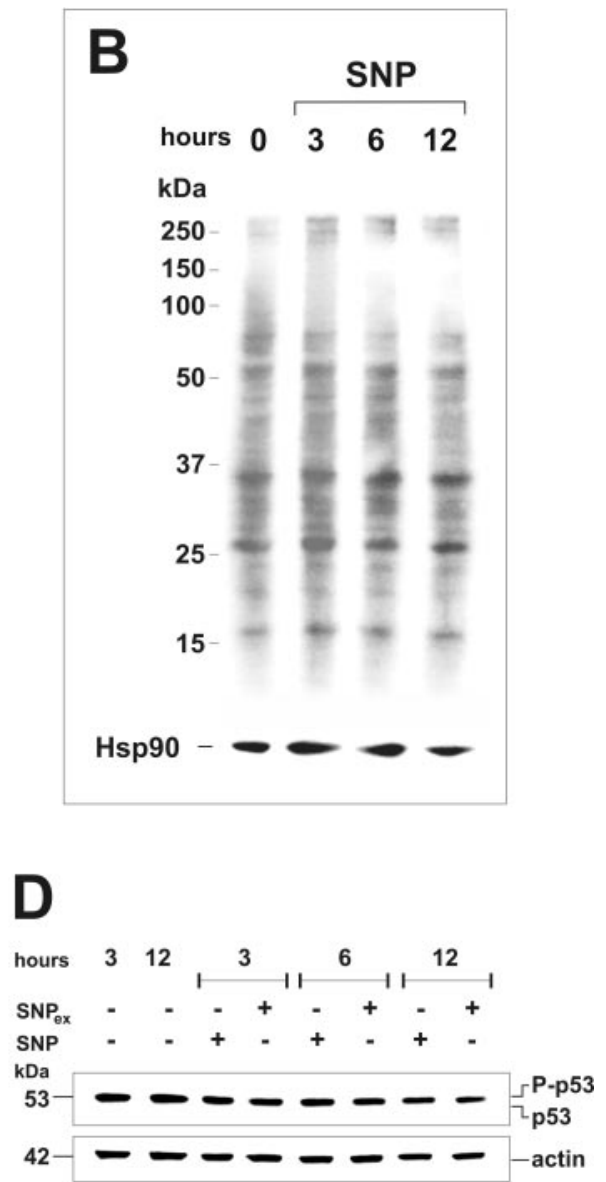

Fig. 7. AGS cells are insensitive to SNP-mediated apoptosis. A, SH-SY5Y and AGS cells were treated with 2 $\mathrm{mM}$ SNP for $24 \mathrm{~h}$ and analyzed for apoptosis extent. Data are expressed as percentage of apoptotic cells and represent the mean \pm S.D. of $n=4$ independent experiments. ***, $p<$ 0.001 . B, AGS cells were treated with $2 \mathrm{mM}$ SNP for different times. Then, $40 \mu \mathrm{g}$ of total protein extracts was reacted with DNP, resolved on $10 \%$ SDS-PAGE, and DNP-derivatized proteins were identified by Western blot using an anti-DNP antibody. Hsp90 was used as loading control. Western blot is from one experiment representative of three that gave similar results. C, AGS cells, treated with $2 \mathrm{mM}$ SNP for $12 \mathrm{~h}$, were used for immunofluorescence analysis of the phosphoactive histone H2A.X (PH2A.X; green). Staining with Hoechst 33342 (blue) was performed to evidence nuclei. D, AGS cells were treated with $2 \mathrm{mM}$ SNP or with equimolar amount of 2-day light-degraded SNP $\left(\mathrm{SNP}_{\mathrm{ex}}\right)$ for different times. Then, $50 \mu \mathrm{g}$ of total protein extract was loaded onto each lane for detection of p53. Actin was used as loading control. Western blots are from one experiment representative of three that gave similar results. P-p53, phosphorylated p53. 
could go beyond that of NO in some conditions, leading to misunderstandings and erroneous interpretations of results.

\section{References}

Boullerne AI, Nedelkoska L, and Benjamins JA (1999) Synergism of nitric oxide and iron in killing the transformed murine oligodendrocyte cell line N20.1. J Neurochem 72:1050-1060.

Brüne B (2005) The intimate relation between nitric oxide and superoxide in apoptosis and cell survival. Antioxid Redox Signal 7:497-507.

Brüne B and Schneiderhan N (2003) Nitric oxide evoked p53-accumulation and apoptosis. Toxicol Lett 139:119-123.

Chen J, Chang B, Williams M, and Murad F (1991) Sodium nitroprusside degenerates cultured rat striatal neurons. Neuroreport 2:121-123.

Ciriolo MR, De Martino A, Lafavia E, Rossi L, Carrì MT, and Rotilio G (2000) Cu, Zn superoxide dismutase-dependent apoptosis induced by nitric oxide in neuronal cells. J Biol Chem 275:5065-5072.

Cosby K, Partovi KS, Crawford JH, Patel RP, Reiter CD, Martyr S, Yang BK, Waclawiw MA, Zalos G, Xu X, et al. (2003) Nitrite reduction to nitric oxide by deoxyhemoglobin vasodilates the human circulation. Nat Med 9:1498-1505.

Feng Z, Li L, Ng PY, and Porter AG (2002) Neuronal differentiation and protection from nitric oxide-induced apoptosis require c-Jun-dependent expression of NCAM140. Mol Cell Biol 22:5357-5366.

Filomeni G, Aquilano K, Rotilio G, and Ciriolo MR (2003a) Reactive oxygen species dependent c-Jun NH2-terminal kinase/c-Jun signaling cascade mediates neuroblastoma cell death induced by diallyl disulfide. Cancer Res 63:5940-5949.

Filomeni G, Aquilano K, Rotilio G, and Ciriolo MR (2005) Glutathione-related systems and modulation of extracellular signal-regulated kinases are involved in the resistance of AGS adenocarcinoma gastric cells to diallyl disulfide-induced apoptosis. Cancer Res 65:11735-11742.

Filomeni G, Cerchiaro G, Da Costa Ferreira AM, De Martino A, Pedersen JZ, Rotilio G, and Ciriolo MR (2007) Pro-apoptotic activity of novel Isatin-Schiff base copper(II) complexes depends on oxidative stress induction and organelle-selective damage. J Biol Chem 282:12010-12021.

Filomeni G, Rotilio G, and Ciriolo MR (2003b) Glutathione disulfide induces apoptosis in U937 cells by a redox-mediated p38 MAP kinase pathway. FASEB $J$ 17:64-66.

Fridman JS and Lowe SW (2003) Control of apoptosis by p53. Oncogene 22:90309040

Friederich JA and Butterworth JF 4th (1995) Sodium nitroprusside: twenty years and counting. Anesth Analg 81:152-162.

Ghatan S, Larner S, Kinoshita Y, Hetman M, Patel L, Xia Z, Youle RJ, and Morrison RS (2000) p38 MAP kinase mediates bax translocation in nitric oxide-induced apoptosis in neurons. J Cell Biol 150:335-347.

Grossi L and D'Angelo S (2005) Sodium nitroprusside: mechanism of NO release mediated by sulfhydryl-containing molecules. $J$ Med Chem 48:2622-2626.

Kim HJ, Tsoy I, Park MK, Lee YS, Lee JH, Seo HG, and Chang KC (2006) Iron released by sodium nitroprusside contributes to heme oxygenase-1 induction via the cAMP-protein kinase A-mitogen-activated protein kinase pathway in RAW 264.7 cells. Mol Pharmacol 69:1633-1640.

Kim SJ, Hwang SG, Shin DY, Kang SS, and Chun JS (2002) p38 kinase regulates nitric oxide-induced apoptosis of articular chondrocytes by accumulating p53 via $\mathrm{NF}_{\kappa} \mathrm{B}$-dependent transcription and stabilization by serine 15 phosphorylation. $J$ Biol Chem 277:33501-33508.

Kotsonis P, Frey A, Fröhlich LG, Hofmann H, Reif A, Wink DA, Feelisch M, and Schmidt HH (1999) Autoinhibition of neuronal nitric oxide synthase: distinct effects of reactive nitrogen and oxygen species on enzyme activity. Biochem $J$ 340:745-752

Lee SJ, Kim DC, Choi BH, Ha H, and Kim KT (2006) Regulation of p53 by activated protein kinase $\mathrm{C}-\delta$ during nitric oxide-induced dopaminergic cell death. $J$ Biol Chem 281:2215-2224.

Li L, Feng Z, and Porter AG (2004) JNK-dependent phosphorylation of c-Jun on serine 63 mediates nitric oxide-induced apoptosis of neuroblastoma cells. $J$ Biol Chem 279:4058-4065.

Lowry OH, Rosebrough NJ, Farr Al, and Randall RJ (1951) Protein measurement with the Folin phenol reagent. J Biol Chem 193:265-275.

Mannick JB (2006) Immunoregulatory and antimicrobial effects of nitrogen oxides. Proc Am Thorac Soc 3:161-165.

Mills EM, Gunasekar PG, Pavlakovic G, and Isom GE (1996) Cyanide-induced apoptosis and oxidative stress in differentiated PC12 cells. J Neurochem 67:1039 1046.

Mohazzab-H KM, Kaminski PM, Agarwal R, and Wolin MS (1999) Potential role of a membrane-bound NADH oxidoreductase in nitric oxide release and arterial relaxation to nitroprusside. Circ Res 84:220-228.

Moncada S, Palmer RM, and Higgs EA (1991) Nitric oxide: physiology, pathophysiology, and pharmacology. Pharmacol Rev 43:109-142.

Nicoletti I, Migliorati G, Pagliacci MC, Grignani F, and Riccardi C (1991) A rapid and simple method for measuring thymocyte apoptosis by propidium iodide staining and flow cytometry. J Immunol Methods 139:271-279.

Pacher P, Beckman JS, and Liaudet L (2007) Nitric oxide and peroxynitrite in health and disease. Physiol Rev 87:315-424.

Rabkin SW and Kong JY (2000) Nitroprusside induces cardiomyocyte death: interaction with hydrogen peroxide. Am J Physiol Heart Circ Physiol 279:H3089 H3100.

Ramakrishna Rao DN and Cederbaum AI (1996) Generation of reactive oxygen species by the redox cycling of nitroprusside. Biochim Biophys Acta 1289:195-202. Rao DN, Elguindi S, and O'Brien PJ (1991) Reductive metabolism of nitroprusside in rat hepatocytes and human erythrocytes. Arch Biochem Biophys 286:30-37.

Rauhala P, Khaldi A, Mohanakumar KP, and Chiueh CC (1998) Apparent role of hydroxyl radicals in oxidative brain injury induced by sodium nitroprusside. Free Radic Biol Med 24:1065-1073.

Schild L, Reinheckel T, Reiser M, Horn TF, Wolf G, and Augustin W (2003) Nitric oxide produced in rat liver mitochondria causes oxidative stress and impairment of respiration after transient hypoxia. FASEB $J$ 17:2194-2201.

Shou Y, Li L, Prabhakaran K, Borowitz JL, and Isom GE (2003) p38 Mitogenactivated protein kinase regulates Bax translocation in cyanide-induced apoptosis Toxicol Sci 75:99-107.

Vousden KH and Lane DP (2007) p53 in health and disease. Nat Rev Mol Cell Biol 8:275-283.

Wang J, Fillebeen C, Chen G, Andriopoulos B, and Pantopoulos K (2006) Sodium nitroprusside promotes IRP2 degradation via an increase in intracellular iron and in the absence of S nitrosylation at C178. Mol Cell Biol 26:1948-1954.

Wink DA, Miranda KM, Espey MG, Pluta RM, Hewett SJ, Colton C, Vitek M, Feelisch M, and Grisham MB (2001) Mechanisms of the antioxidant effects of nitric oxide. Antioxid Redox Signal 3:203-213.

Yu J and Zhang L (2005) The transcriptional targets of p53 in apoptosis control Biochem Biophys Res Commun 331:851-858.

Address correspondence to: Dr. Maria R. Ciriolo, Department of Biology, University of Rome "Tor Vergata,"Via della Ricerca Scientifica, 00133 Rome, Italy. E-mail: ciriolo@bio.uniroma2.it 